\title{
A agroecologia entre a realidade e a teoria: encontros e desencontros entre a institucionalização, a prática e a militância
}

Manoel Adir Kischener ${ }^{1}$

Danieli Simonetti ${ }^{2}$

Elize Bertella ${ }^{3}$

\begin{abstract}
Resumo
O artigo apresenta, no primeiro momento, parte do debate conceitual que envolve a Agroecologia e sua diversidade. Na sequência, apresenta-se a realidade encontrada em três experiências visitadas no Estado do Paraná: uma ONG (o CAPA, em Verê, na região Sudoeste), uma instituição estatal (o CPRA, em Curitiba, região metropolitana) e um movimento social (o Assentamento 8 de Junho, em Laranjeiras do Sul, na Região Sul). A partir do debate conceitual e da realidade constatada questiona-se: afinal, qual é a alternativa possível dentro do debate de Agroecologia?
\end{abstract}

Palavras-chave: Agroecologia. Conceito. Produção. Comercialização.

\begin{abstract}
The paper presents part of the Agroecology conceptual debate and its diversity. The following is the reality found in three experiments visited in Paraná, an ONG - CAPA in Verê, on the southwest -, a state institution - the CPRA in Curitiba metropolitan region -, a social movement - the Assentamento 8 de Junho in Laranjeiras do Sul, in the South. From the conceptual debate and found reality the question is: which is a possible alternative in the debate Agroecology?
\end{abstract}

Keywords: Agroecology. Concept. Production. Commercialization.

\section{Do conceito à realidade}

O termo ou conceito Agroecologia tem sido usado de forma recorrente nas últimas décadas, nem sempre com uma conotação específica e uma definição alojada ${ }^{4}$, o

\footnotetext{
${ }^{1}$ Professor de História, Mestrando em Desenvolvimento Regional na UTFPR. kischener@hotmail.com

2 Engenheira Agrônoma, Mestranda em Desenvolvimento Regional na UTFPR. danisimo.slo@gmail.com

${ }^{3}$ Professora de Educação Física, Mestranda em Desenvolvimento Regional na UTFPR. elizedv02@hotmail.com

${ }^{4}$ Por "definição alojada" entende-se o fato de que a palavra agroecologia tem muitas interpretações, e, por vezes, é usada sem que se deixe claro qual é o seu significado para determinado autor.
} 
que, por vezes, gera fortes críticas.

Este artigo procura discutir como o conceito de Agroecologia é percebido em algumas experiências, qual é a concepção teórica que as organizações assumem e, na prática, como este conceito se aplica, quando se aplica.

Como parte da construção deste trabalho, foram visitadas três experiências do Estado do Paraná, uma ONG (o CAPA, em Verê, na região Sudoeste), uma instituição estatal (o CPRA, em Curitiba, região metropolitana), um movimento social (o Assentamento 8 de Junho, em Laranjeiras do Sul, na Região Sul). Essas visitas tiveram o propósito de conhecer as diferentes realidades que vivenciam experiências agroecológicas, sejam elas práticas (no sentido da assistência técnica e extensão, com a ONG), institucionais (teórico-práticas na instituição estatal), práticas (de cultivo no assentamento). Com isso se busca fazer um diagnóstico do estado da arte e prático da Agroecologia no Estado do Paraná5.

As correntes ou escolas da dita agricultura alternativa são colocadas por vários autores, as mais citadas são a Orgânica; a Biodinâmica; a Permacultura; a Natural; a Biológica; a Alternativa e a Agroecológica. Há especificidades, mas as convergências entre elas são maiores. Todas as correntes se propõem a ser alternativas ao modo convencional, com a produção de alimentos saudáveis, livres de resíduos agroquímicos sintéticos.

A Agroecologia surge na década de 1930 como sinônimo de ecologia aplicada à agricultura (GLIESSMAN, 2000) e populariza-se, nos anos 1980, a partir dos trabalhos de Miguel Altieri e, posteriormente, de Stephen Gliessman (GUHUR, TONÁ, 2012).

Segundo Caporal (2009, p. 3), a Agroecologia não pode ser confundida com agricultura orgânica e também "não é pertinente confundir Agroecologia com um tipo de agricultura alternativa". O autor e outros afirmam que as correntes da agricultura alternativa não seguem as premissas da Agroecologia, a qual possui um sentido mais amplo do que apenas a troca de insumos químicos convencionais por insumos alternativos ou orgânicos. Para ele, Agroecologia seria mais que um modo de produzir, vê como uma "filosofia", um modo de vida, cuja preocupação está voltada às dimensões econômica, social e ambiental (CAPORAL; COSTABEBER; PAULUS, 2006; CAPORAL, 2009).

Para Caporal, Costabeber e Paulus (2006), a Agroecologia é mais do que um manejo ecológico correto, mas sim um campo científico que parte "de um enfoque holístico e de uma abordagem sistêmica". Ainda, os autores acreditam que a Agroecologia contribui "para que as sociedades possam redirecionar o curso alterado da coevolução social e ecológica, nas suas múltiplas inter-relações e mútua influência". Indo além, afirmam que a Agroecologia, enquanto ciência integradora de distintas disciplinas científicas, "tem a potencialidade para constituir a base de um novo paradigma de desenvolvimento rural sustentável" (CAPORAL; COSTABEBER; PAULUS, 2006, p. 3).

Caporal (2009, p. 9) corrobora com a afirmação e coloca a Agroecologia como uma quebra de paradigma; no entanto, este mesmo autor alerta que a Agroecologia não oferece "uma teoria sobre desenvolvimento rural, sobre metodologias participativas e, tampouco, sobre métodos para a construção e validação do conhecimento técnico".

Com base nesse cenário, Navarro (2013) critica fortemente o debate da Agroeco-

\footnotetext{
${ }^{5}$ Para um histórico do processo de institucionalização, por assim dizer, da Agroecologia no estado do Paraná, consulte-se IPARDES (2007, p. 44-47).
} 
logia no Brasil. O autor reconhece que há exceções, mas afirma que, na grande maioria, a Agroecologia é tratada como algo já consumado, conhecido, desconsiderando a necessidade de uma apresentação conceitual do termo e a falta de clareza sobre quais seriam os seus princípios.

Em relação à crítica de ser ou não uma ciência, Wezel et al. (2009) sustentam que há evidências convincentes de que a Agroecologia é uma ciência, citando Dalgaard, Hutchings e Porter (2003), mas que sua conclusão somente pode ser aplicada para a sua definição específica. Dessa forma, os autores afirmam que "não se deve assumir automaticamente que 'Agroecologia' é uma ciência sem dar um sentido preciso da palavra" (WEZEL et al., 2009, p. 511, tradução nossa' ${ }^{6}$ ).

A partir do histórico do termo Agroecologia, Wezel et al. (2009, p. 511, tradução nossa) apresentam três abordagens interligadas: uma "visão política (o movimento), uma aplicação tecnológica (a prática), para atingir as metas, e uma maneira de produzir o conhecimento (a ciência) $)^{7 \prime \prime}$.

Para estes autores, a preferência por uma ou outra abordagem depende, nos casos estudados, dos autores da evolução histórica do país. Nos EUA, por exemplo, a Agroecologia foi sendo explorada inicialmente por cientistas que estudavam a poluição ambiental da agricultura; já no Brasil, a base da Agroecologia vem de diferentes movimentos sociais que estimularam práticas alternativas e, nos últimos anos, vem sendo considerada uma disciplina científica, com "base em uma adaptação da interpretação científica de Agroecologia dos EUA com uma integração das dimensões sociais"8 (WEZEL et al., 2009, p. 508, tradução nossa).

O pesquisador Sthephane Bellon, durante o Seminário de Agroecologia Brasil e França, realizado pelo IAPAR, em dezembro de 2013, coloca a Agroecologia como um campo científico em construção, como "um verdadeiro canteiro de obras", e ainda que "a diversidade (da Agroecologia) é reflexo da grande abrangência adquirida nas últimas décadas e deve ser valorizada" (IAPAR, 2013, p. 2).

Norder (2013) também reconhece a diversidade e a multiplicidade de conceitos de Agroecologia, citando os diversos discursos (analítico, normativo, programático) presentes nos diversos campos (ciência, movimentos sociais, política e educação), que atribuem ao termo cada qual a sua especificidade, e debatendo a sua abrangência (delimitando a agricultura familiar, camponeses, povos tradicionais e agronegócio).

O autor ainda apresenta duas importantes concepções para Agroecologia, uma como processo produtivo, e outra como processo de conhecimento. Sugere que, ao invés de considerar a Agroecologia como uma ciência em construção, seria mais prudente considerá-la como um "conhecimento que precisa ser construído por cada ator e o debate deve ser conduzido com respeito ao outro, já que a controvérsia é parte inexorável da construção deste conhecimento" (NORDER, 2013). Dessa forma, faz sentido a multiplicidade de conceitos e de diferentes princípios, porque cada ator precisar conhecer as

\footnotetext{
6 "One should not automatically assume that "agroecology" is a science without giving a precise meaning to the word".

7 "A political vision (the movement), a technological application (the practices) to achieve the goals, and a way to produce the knowledge (the science)".

8 "Based on an adaptation of the U.S. scientific interpretation of agroecology with an integration of social dimensions".
} 
diferenças e chegar a que considera mais adequada. É com essa perspectiva de multiplicidade e multidimensionalidade que este artigo irá trabalhar, procurando perceber o sentido da Agroecologia nas organizações visitadas.

\section{Impressões das experiências visitadas}

\subsection{O CAPA - Centro de Apoio ao Pequeno Agricultor}

O Centro de Apoio ao Pequeno Agricultor (CAPA) é uma organização não-governamental (ONG), criada em 1978, com o intuito de atender somente produtores rurais com pequena quantidade de terra. Conforme a própria entidade, "Trabalha-se pela afirmação da agricultura familiar como parte de uma estratégia de desenvolvimento rural sustentável" (CAPA, 2013).

A atuação do Centro ocorre nos Estados do Rio Grande do Sul, com três núcleos, Erechim, Pelotas e Santa Cruz, e no Estado do Paraná, com dois núcleos, Verê e Marechal Cândido Rondon. O CAPA procura trazer propostas alternativas de produção, contrapondo-se aos pacotes da modernização e aos vínculos de dependência criados pela integração do pequeno agricultor familiar à agroindústria de alimentos.

Conforme dados da própria ONG, esta trabalha com a agricultura familiar de forma geral, mas sua origem está ligada à Igreja Evangélica de Confissão Luterana no Brasil (IECLB) e a seus imigrantes e descendentes de alemães. Com as dificuldades encontradas na colonização da região Sul, a redução do número de membros e o empobrecimento dos que não estavam aderindo à "Revolução verde" serviço específico para os agricultores familiares, criando, assim, em 1978, o Centro de Aconselhamento ao Pequeno Agricultor, na cidade de Santa Rosa (RS). Em 1982, criou-se uma unidade em São Lourenço do Sul (RS) e, mais tarde, outra em Santa Cruz do Sul (RS). Em 1988, o Centro de Santa Rosa foi transferido para Erechim. Ainda em 1988, mudouse o nome para Centro de Apoio ao Pequeno Agricultor, permanecendo a mesma sigla (CAPA). Em 1997, foram criados dois núcleos no Paraná, em Verê e Marechal Cândido Rondon (CAPA, 2013). O núcleo de Verê é o foco deste item.

O Centro recebe apoio financeiro da Organização Protestante para a Diaconia e o Desenvolvimento (Evangelisches Werk für Diakonie und Entwicklung), com sede em Berlim (Alemanha), e também faz parcerias com os municípios; atualmente possui convênio com os municípios de São Jorge do Oeste, Itapejara d'Oeste, Verê, e atende alguns produtores de Pato Branco (CAPA, 2013).

A visita ao CAPA se deu em um dia: pela manhã, fomos recebidos na sede da ONG e informados da história, dos objetivos e missão da entidade, pela coordenadora e por um dos técnicos, em uma reunião em que estavam presentes produtores da região que também visitam a entidade neste "dia de campo", por assim dizer. Posteriormente, visitou-se o mercado da APAVE e a propriedade modelo, que pertence a um dos técnicos.

\footnotetext{
${ }^{9}$ Entende-se como "Revolução verde" a entrada de agroquímicos para controle de plantas invasoras, pragas e doenças, e também a utilização de adubos sintéticos de alta solubilidade. Para mais detalhes, ver: SCHNEIDER (2000).
} 
O CAPA possui uma equipe composta por três técnicos e uma coordenadora. Os técnicos possuem experiência com a produção orgânica e, de forma geral, mostram-se preparados para atender às demandas vindas dos produtores assistidos pela ONG.

Um dos técnicos é produtor orgânico e possui, na sua propriedade, o que chama de estação experimental do CAPA, local em que são testadas novas variedades, verificando-se se são ou não adaptadas à região, a utilização de novos produtos, formas de produção, construções, investimentos em novas culturas. É nesta propriedade, que também tem fins lucrativos, que são realizados vários experimentos. Esse método permite que, ao repassar as informações ao produtor, os técnicos já tenham informações de campo específicas para aquela região.

Segundo informações da coordenadora da entidade, o maior número de produtores orgânicos se encontra no município de Verê, são 34 os certificados e assistidos pelo CAPA, e, ao total, são quase 50 na região. A estes, a ONG faz visitas regulares e presta assistência técnica, também auxilia na organização de associações de produtores quando há solicitação. A certificação obtida provém, em sua maioria, da rede $\operatorname{ECOVIDA}^{10}$, o que diminui os custos de uma certificação para o produtor.

No município de Verê, a maior colaboração da ONG é com a Associação de Produtores Agroecológicos de Verê (APAVE). Conforme relato dos integrantes da entidade, a associação está consolidada há mais de 12 anos. Além de vender produtos in natura, agrega valor, a partir do processamento em compotas, conservas e doces.

Conforme foi exposto pelos integrantes da associação, na cozinha industrial, inicialmente, eram processadas as "sobras" dos produtos comercializados, mas atualmente a maior parte da produção visa atender especificamente o processamento. A agregação mantém um mercado onde comercializa os produtos dos agricultores, hortaliças, frutas, vinho e artesanatos. Com o fluxo de caixa, consegue pagar os produtores na hora, sem necessidade de espera pela venda, principalmente quando a produção vai para a industrialização.

O mercado da APAVE, conforme informam os seus integrantes, junto com o CAPA, oferece insumos (sementes, adubos orgânicos, lonas de estufas, etc.) aos produtores associados e atendidos, oferecendo-Ihes prazos e condições de pagamento, de acordo com as suas possibilidades, sem a cobrança de juros, para favorecer o acesso a materiais de qualidade e com preço acessível.

Parte da comercialização dos produtos e produção da associação é realizada via mercado institucional, através dos programas PAA (Programa de Aquisição de Alimentos) e PNAE (Programa Nacional de Alimentação Escolar), com o acréscimo de $30 \%$ por ser produção orgânica. Além desses mercados institucionais, conforme relato dos associados, há outras possibilidades de comercialização na região; as redes de supermercados não são atendidas na totalidade por falta de produtos, provavelmente, se ocorresse uma produção maior, o mercado estaria garantido, apostam.

O corpo técnico do CAPA e da APAVE informa que a intenção é alcançar a susten-

\footnotetext{
$\overline{{ }^{10} \text { É uma entidade }}$ de agricultores, associações e movimentos que visa à certificação de forma participativa. Para mais detalhes da organização, ver em: ROVER (2011).
} 
tabilidade da propriedade, independente do tamanho da produção e do lucro que pode gerar ou não para a associação, sendo importante que o produtor consiga se manter no meio rural, objetivo em que acredita.

\section{Aspectos negativos}

A equipe técnica se mostra preparada para atender os agricultores, no entanto é limitada em número, apenas três técnicos para atender à região, se outros municípios decidirem fazer parcerias, não haverá pessoal suficiente para levar assistência técnica. A limitação de pessoal também dificulta trabalhar com a produção animal, que é de maior complexidade e exigiria um profissional especializado na área.

A visita realizada foi apenas na propriedade de um dos técnicos (modelo), ficando a dúvida sobre a efetividade da transmissão de conhecimentos nos demais estabelecimentos. A produção de mudas de hortaliças para os produtores do município de Verê fica em parte concentrada também nesta propriedade.

A falta de investimentos e de interesse, apontada pela ONG, por parte do poder público nos municípios onde atua, dificulta o trabalho. Assim, possivelmente, sem a pressão dos produtores, não serão realizados convênios.

Apesar da equipe técnica do CAPA afirmar que a organização é uma instituição diferente da APAVE, as duas se confundem em muitos aspectos, deixando a impressão de que a associação somente existe e se mantém com o apoio e, provavelmente, a intervenção do CAPA. São os técnicos da ONG que organizam o mercado e a industrialização. Esta junção entre as diferentes instituições pode se dar pelo fato de um dos técnicos do CAPA ser também produtor da associação e demonstrar influência nas decisões desta. Seria difícil falar do CAPA Verê sem que se tenha referências sobre a APAVE. Não se pode negar que a APAVE faz parte do portfólio do CAPA.

A agregação de valor realizada na APAVE com a marca registrada pelo CAPA (Vereda ecológica) eleva a taxa de aproveitamento dos produtos, mas a maior beneficiária acaba sendo a associação, pois o produtor recebe pelo produto in natura.

\section{A Ong e a prática: questionamentos e reflexões}

Como o núcleo está situado no município de Verê, é neste que se encontra a maior parte dos produtores e os maiores esforços da ONG. Mesmo sendo este um dos menores municípios da região, conta com 34 dos 50 certificados. Será esta disparidade consequência da falta de interesse político dos municípios, da comodidade da organização ou, ainda, da limitação técnica?

Há certa dificuldade em se tirar conclusões da efetividade da assistência técnica realizada pelo CAPA, pois a única propriedade visitada é a de um dos técnicos da organização. Dessa forma, não se pôde avaliar se realmente a assistência está tendo efetividade quanto aos demais produtores. Este estabelecimento contava com um funcionário contratado, deixando em aberto a questão: até que ponto os produtores darão conta de manter a sua propriedade somente com a família, sem a necessidade de contratação de força de trabalho? Se o CAPA visa à permanência do produtor no meio rural, obtendo 
seu sustento a partir da renda da sua produção, como explicar que, na propriedade visitada, o casal (técnico e cônjuge) trabalhe fora do estabelecimento? De que estratégias se utilizam os demais estabelecimentos?

Para a coordenadora do CAPA, não se tem mais a ideia tradicional de que o produto orgânico seria menor, feio, com parte estragada; segundo ela, atualmente são produtos de qualidade e com boa aparência. No entanto, um dos benefícios apontados para a agroindustrialização é o aproveitamento de produtos menores, sem apelo comercial, quando vendidos in natura. Qual das afirmações é mais relevante?

Ponderando que a produção agroecológica considera o estabelecimento agrícola como um único sistema, percebe-se, nas explanações, que os agricultores assistidos pelo CAPA trabalham de forma agroecológica somente numa parte dos estabelecimentos. Este não é um ponto negativo; no entanto, é contraditório, pois a missão e os princípios da ONG somente mencionam a Agroecologia como um sistema.

O CAPA, mesmo com os aspectos questionáveis citados acima, se mantém dentro dos princípios que estabeleceu, ocorrendo equívocos na utilização de termos (parágrafo anterior), mas não os cometendo, ao que se deduz, de má fé ou de forma ideológica.

\subsection{O CPRA - Centro Paranaense de Referência em Agroecologia}

O CPRA foi instituído como uma autarquia por decreto governamental em 28 de dezembro de 2005 (CPRA, 2013). Está localizado na Estrada da Graciosa, 6960, Parque das Nascentes, município de Pinhais, região metropolitana de Curitiba. Tem como missão "Comunicar, promover e apoiar ações de capacitação, pesquisa, ensino e articulação entre pessoas e organizações", sendo estas "voltadas à produção agropecuária e ao consumo sustentáveis, baseados nos preceitos da Agroecologia", com a visão de "Ser referência na orientação de ações para a expansão da Agroecologia", com o propósito de atender "Agricultores, técnicos, estudantes, educadores, consumidores e representantes de organizações públicas e privadas com responsabilidade na produção e consumo sustentáveis", ressaltando que "são prioritários os públicos da agricultura familiar e comunidades tradicionais, oriundos de regiões com menores índices de desenvolvimento humano" (CPRA, 2013).

Ainda, conforme Miranda, Zandoná e Coelho (2011) destacam, o CPRA passou por reformulação em 2011, agora com duas abrangências: "regional, na Estação Agroecológica em Pinhais", e "estadual, pela Rede de Agroecologia" (MIRANDA; ZANDONÁ; COELHO, 2011, p. 1).

A visita ao CPRA contou com uma breve reunião com os pesquisadores do Centro, quando foi apresentado o vídeo institucional com a história e a estrutura física e humana da autarquia; na sequência, uma visita à área experimental do Centro. Na companhia de um dos técnicos, realizou-se também visita a uma propriedade assistida pela instituição.

\section{Aspectos positivos}

O CPRA possui grande estrutura (deteriorada em alguns pontos, mas grande), e poderá, com isso, agilizar suas ações prioritárias, conforme exposto em sua proposta, 
com "ações de difusão, capacitação, pesquisa e validação nas áreas temáticas de Recursos Naturais, Produção Vegetal Integrada, Produção e Bem Estar Animal e Engenharia Alternativa" (MIRANDA; ZANDONÁ; COELHO, 2011, p. 1).

$\mathrm{Na}$ área, foi feita a transição, isto é, a desintoxicação do solo, com experiências no âmbito da produção de hortaliças e frutas orgânicas, no sentido de prestar assessoria técnica à produção já existente nas regiões metropolitanas de Curitiba e Litoral, regiões com expressiva produção de hortaliças e frutas, com o intuito de abastecer o mercado metropolitano, em crescente expansão (MELÃO, 2010).

Estrategicamente, encontra-se localizado ao lado do campus da Universidade Federal do Paraná (UFPR), também, dada a constituição da região metropolitana, está próximo dos agricultores, o que poderia auxiliar na difusão das experiências, conforme estabelecem suas diretrizes.

Conforme relato dos integrantes do Centro, atualmente se dispõe de recursos para a contratação de estagiários para atender à diversidade demandada.

Parte da equipe, pesquisadores e funcionários de campo, encontra-se motivada, e, pelo que se observou, com capacitação para o exercício das atividades nos propósitos da Agroecologia.

\section{Aspectos negativos}

Da mesma forma que pode ser positivo ter uma grande estrutura, isso pode acarretar um ônus e até atravancar as ações, na ausência de equipe adequada, ou seja, em número suficiente. O Centro possui estrutura humana deficitária para atender a toda a sua extensão, a maioria do serviço de campo é realizado por estagiários, faltando funcionários efetivos para os trabalhos de campo, resultando em estrutura e terrenos subutilizados.

Constatou-se, na visitação, que as experiências ou ações dos dois técnicos mais ativos no CPRA estão centradas na produção de leite (especialmente em manejos no estilo pastoreio racional Voisin) e pouco na horticultura (apesar das estufas de bambu). $\mathrm{Na}$ rápida visita, constatou-se que a região em que se localiza a instituição está mais voltada ao plantio de hortaliças do que propriamente à pecuária leiteira.

Apesar da proximidade com outras instituições, como UFPR, Embrapa e os próprios órgãos municipais da região, parece não ocorrer comunicação entre eles, nem destes com os produtores, pois os agricultores visitados comentaram que pouco se conhece da ação prática do CPRA. Essa falha na comunicação acaba provocando o distanciamento entre a teoria e a prática (algo caro aos princípios ditos agroecológicos).

Devido ao déficit de servidores para atuar na parte operacional do Centro, os pesquisadores e os estagiários precisam despender muito tempo com tarefas diárias e rotineiras (limpeza de estábulo, capina, compostagem, entre outras), o que dificulta o avanço nas pesquisas já existentes e o estabelecimento de novas.

É possível perceber, no discurso e nas ações, que parte da equipe ainda não assimilou a transição agroecológica, contradizendo, assim, as missões e os princípios da instituição (e do que propriamente propaga, a Agroecologia). 
O CPRA não é um órgão de extensão rural, também não é uma estação de pesquisa nem tem uma forte difusão de tecnologias, uma mistura que acaba sendo pouco efetiva em seus propósitos formativos; assim, pode-se dizer que vive uma crise de identidade institucional? Qual é então o propósito do CPRA? O que deve fazer, pesquisa, extensão ou escola demonstrativa? Qual o papel do CPRA no estado do Paraná? Os agricultores o conhecem?

De acordo com o que já foi descrito, missão e visão buscam promover a articulação entre organizações públicas e privadas, no entanto não é isto que se percebe no CPRA; por exemplo, mesmo alocado próximo à EMBRAPA e à UFPR, não consegue manter parcerias efetivas. Qual a dificuldade de estabelecer parcerias com as demais organizações, mesmo tendo foco em agricultura e desenvolvimento e sendo também órgão do poder público? Por que há tanta incompatibilidade entre setores públicos (onde se espera uma sintonia e sincronia)?

O CPRA não possui um quadro funcional próprio, os pesquisadores que ali estão são cedidos de outras instituições estaduais, a pedido ou atendendo ao interesse da administração. Quando se trata de uma transferência a pedido, pode-se afirmar que o técnico tem uma postura profissional, identificada com os ideais da Agroecologia e com a missão da instituição; no entanto, pode ser resultado de um não encaixe às demais instituições, o que resultaria num deslocamento para o CPRA, fato que é perceptível nas transferências atendendo ao interesse da administração. Como identificar se os funcionários do CPRA estão lá motivados pela missão, por funções burocráticas ou, então, por cederem a motivações ou desentendimentos político/partidários ${ }^{11}$ ? Os interesses ficam somente no estrito horário de trabalho ou vão além? Seu pessoal técnico é capacitado para trabalhar com a produção agroecológica?

Várias experiências são realizadas no tocante à biodinâmica, bioconstruções e manejo animal, algumas repassadas por meio de cursos e cartilhas. Porém algumas dessas experiências não se mostram práticas de serem realizadas; por exemplo, os compostos da biodinâmica, que exigem cuidados específicos e grande dedicação de tempo, os quais nem sempre o agricultor consegue executar na propriedade, além de que sua utilização depende da crença na mística que os envolve. Com a grande difusão de produtos prontos e de rápido funcionamento, não haveria necessidade de também envolver outras experiências de ação em curto prazo?

\subsection{Assentamento 8 de Junho}

Assentamento da reforma agrária, localizado às margens da BR 158, no município de Laranjeiras do Sul, teve seu início no dia 8 de junho de 1997, quando um grupo composto por dezessete famílias ocupou a entrada da Fazenda Rio do Leão (CEZIMBRA, 2013; MARTIGNONI, 2013). A disputa pela posse da terra com os fazendeiros durou cerca de

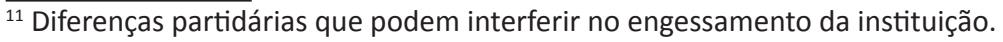


quatro anos, e, então, a área foi desapropriada pelo INCRA em 2001 (MARTIGNONI, 2013).

Segundo os assentados, as dificuldades encontradas foram muitas, sofreram com ameaças de pistoleiros armados que, constantemente, rondavam o acampamento, colocando em risco a vida de todos que ali estavam. Também citam dificuldades com relação a necessidades básicas, como alimentação, saúde, educação e segurança, que fizeram com que muitas famílias vivessem períodos separados, quando a mãe e os filhos permaneciam em casas de familiares, e o pai, no acampamento. As famílias assentadas relataram que contavam com a ajuda de familiares e dividiam o que tinham entre o grupo para sobreviver.

Para Campos (2011), foram muitas as dificuldades encontradas, a organização e a solidariedade entre os assentados foram importantes para manter o grupo unido, a partir de ações, como festas em datas comemorativas, como Dia dos Pais, das Mães, Dia da Criança e aniversário do Assentamento, as quais ainda são mantidas.

$\mathrm{O}$ assentamento conta com 74 lotes, dos quais três foram doados à Universidade Federal da Fronteira Sul (UFFS) - Campos de Laranjeiras do Sul. No ano de 2003, iniciou-se a discussão da produção orgânica, e, no ano de 2007, foi fundada a Cooperativa Agroindustrial 8 de Junho (COOPERJUNHO), conforme informaram os assentados. Neste mesmo ano, foi iniciada a feira orgânica, na cidade de Laranjeiras do Sul, e o acesso ao PAA.

A visita ao Assentamento foi iniciada com uma reunião, no período da manhã, da qual participaram os pesquisadores e os produtores, momento em que foi oportunizada a discussão sobre os conceitos e a prática da Agroecologia, e os produtores puderam descrever um pouco da trajetória do Assentamento e a forma como a produção foi adotada. No período da tarde, foram realizadas visitas a quatro propriedades para o conhecimento em loco do sistema de produção adotado em cada uma.

\section{Aspectos positivos}

A COOPERJUNHO ${ }^{12}$ é uma estratégia da comunidade, para abrir postos de trabaIho, com o intuito de elevar a renda familiar e manter o jovem próximo ao campo (na questão sucessória, por exemplo), com a possibilidade de aumentar a força de trabalho disponível e a qualidade de vida das famílias.

A cooperativa conta com uma panificadora e, atualmente, está com o projeto de um laticínio; com a instalação deste último, será possível abrir pelo menos 200 postos de trabalho, conforme relataram os assentados. A expectativa deles é de que o laticínio poderá beneficiar desde o produtor e sua família, que fornecem a matéria-prima, até os novos trabalhadores assalariados da cooperativa.

${ }^{12}$ A Cooperativa Agroindustrial 8 de Junho, conforme consta em seu estatuto, tem por objetivos: promover a implantação de Agroindústrias destinadas ao beneficiamento de leite e seus derivados, de cana-de-açúcar e seus derivados, produtos da agricultura e da pecuária, de hortifruticulturas, de panificação e confeitaria, de produtos florestais, de mel e seus derivados; bem como embalagem de artesanato, buscando o desenvolvimento sustentado nas áreas ambiental, econômica e social proporcionando aos agricultores familiares a melhoria na qualidade de vida. 
A cooperativa é organizada e comandada pelos próprios agricultores. O acesso ao crédito é consideravelmente fácil, devido a políticas públicas voltadas para a reforma agrária e para as cooperativas de produtores, informaram os cooperados.

Conforme relataram os assentados, o 8 de Junho estabelece parcerias com docentes da UFFS, os quais, através de projetos, auxiliam na formação de lideranças, nos processos produtivos, na organização e administração da cooperativa. Segundo eles, vários jovens, filhos de assentados, estão cursando graduações na Universidade. Por meio desses jovens, já são desenvolvidos alguns projetos, e pretende-se desenvolver novos projetos no assentamento, fato que é valorizado e apoiado pelas famílias e pela comunidade, pois a contribuição desses jovens poderá ser fundamental uma vez que a junção entre formação acadêmica e participação e formações do Movimento auxiliam no reconhecimento do processo evolutivo desta realidade, defenderam os assentados.

Percebendo que a feira dos produtores não absorvia toda a produção, mas que também não teriam produção para grandes mercados, a estratégia adotada pelos assentados foi utilizar a cozinha da cooperativa para suprir esta sobre-oferta, e, assim, o produtor não perde produto e se motiva a continuar. Com isto, a cozinha passou a ser utilizada para a produção de marmitas, aumentando a variedade de produtos oferecidos pela cooperativa e, consequentemente, o lucro.

O laticínio do assentamento será o primeiro laticínio orgânico do Estado do Paraná, um investimento, segundo os assentados, de mais de 15 milhões do Governo Federal. A produção interna do assentamento possivelmente não será suficiente para a capacidade de produção, então poderão abrir espaço para que outros agricultores do município possam se associar à cooperativa para fornecer leite orgânico.

\section{Aspectos negativos}

Na produção de leite orgânico, os agricultores estão encontrando dificuldades, principalmente para a alimentação e sanidade, uma vez que não se utiliza de suplementos e medicamentos sintéticos, além do manejo das pastagens e grãos necessários para alimentação, os quais também precisam ser orgânicos.

As famílias relatam que tiveram dificuldade para obter a certificação, pois o processo de transição, muitas vezes, implica na diminuição de produção e, consequentemente, da renda familiar de tais atividades. Segundo uma das produtoras, "os três primeiros anos, se você não tiver outra fonte de renda, você passa necessidade, porque a gente perde produção até o agrossistema estar preparado para a produção orgânica. A legislação deveria estar a nosso favor e não a favor dos convencionais, quem planta convencional deveria fazer as barreiras de proteção"13.

A falta de equipamentos adaptados à produção orgânica é uma dificuldade enfrentada pelos produtores do assentamento, e as políticas públicas ainda não têm linha de financiamento para aquisição desses equipamentos; no entanto, "os equipamentos existem, e a gente até conhece alguns, mas, por falta de dinheiro e até de mais interesse, não fomos atrás", afirma outra agricultora ${ }^{14}$.

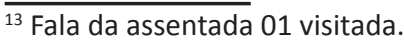

${ }^{14}$ Fala da assentada 02 visitada.
} 
Os cursos de Agronomia, Medicina Veterinária e Zootecnia da região são voltados à produção convencional, e os técnicos não conseguem dar a assistência necessária e adequada à produção orgânica. Sendo assim, falta assistência técnica especializada que auxilie na resolução dos problemas encontrados na produção orgânica; no entanto, o campus da UFFS agora iniciou cursos com ênfase em Agroecologia, o que, futuramente, pode minimizar tais gargalos.

Apesar de algumas articulações com servidores da Universidade, os assentados acreditam que poderia haver um maior número de ações, além de maior articulação na elaboração dos projetos, considerando as necessidades e anseios da comunidade.

Os assentados reclamaram que o assentamento é alvo de várias pesquisas de diferentes instituições, porém não há retorno dos resultados, como se percebe nesta fala: “O pessoal vem aqui, faz um monte de questionário e vai embora, a gente nem sabe o que eles estão escrevendo sobre nós". ${ }^{15}$

O mesmo agricultor afirmou que "depois de 10 anos de caminhada, precisamos de ações práticas. Cursos de formação e pesquisa de diagnóstico foram realizados aos montes, o que a gente precisa é de pesquisa aplicada", sugerindo como necessidade o melhoramento de semente e o controle de pragas, como a lagarta e o caramujo.

Falta iniciativa da comunidade em se desafiar em busca de novas opções que meIhorem as condições de trabalho. Conforme relato de uma das lideranças no momento da visita, "a maior dificuldade é se desapegar de um sistema convencional, para outro sistema que dá retorno de forma gradativa e prolongada", e ainda outro agricultor complementa que "falta a gente se desafiar, falta a cooperativa se desafiar para dar subsídio para os produtores" 16 .

\section{Impressões da visita}

As propriedades visitadas estão no processo de transição; conforme apregoa a Agroecologia, possuem certificado agroecológico, mas reconhecem que o que fazem é produção orgânica, com pequenas hortas e pomares, e início de produção leiteira, que não abrange todo o estabelecimento. Apesar de perceber nas falas um enquadramento como agricultor orgânico, grande parte deles se mantém com rendas do trabalho assalariado na cooperativa e em algumas indústrias e também, em alguns casos, acessam os benefícios de programas sociais do Governo Federal. A produção orgânica não chega a ser a principal fonte de renda de nenhum dos assentados.

Observando os princípios da reforma agrária e do cooperativismo com deliberação e gestão participativa, fato que nos chamou a atenção durante a visita foi a percepção de que a direção da cooperativa, desde a sua fundação, está sob o comando de pessoas da mesma família, sendo os que ocupam os cargos de poder decisório e mais rentáveis. Dessa forma, questiona-se: Por que não há uma rotatividade de direção? São os demais cooperados que não se propõem a participar destes cargos, ou ocorre falta de espaço para esta participação? E, ainda, por que há aproximadamente 40 famílias do próprio assentamento que não aderiram à cooperativa, já que apenas 30 das 71 fazem

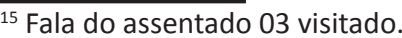

${ }^{16}$ Fala do assentado 04 visitado.
} 
parte dela?

Os cooperados afirmam que hoje o retorno financeiro é o que segura o jovem no campo, então as estratégias deveriam ser planejadas para que se tenham rendas que garantam a permanência deste público para manter a cooperativa ativa. Este ponto de vista pode ter dois focos, o primeiro no sentido de que os empregos assalariados mantêm os jovens no meio rural (moradia), mas não em função do agrícola. O segundo é um contraponto, segundo o qual a compra dos produtos pela cooperativa resulta no incentivo da produção agrícola, na elevação da renda e na permanência no campo (moradia + trabalho).

\section{Considerações finais}

As dificuldades do período de transição (convencional/agroecológico) estão relacionadas a diversos fatores, dentre eles o econômico, que pode ser o mais preponderante numa decisão de desistência. Quando se fala em pequenos produtores, que não têm nenhum tipo de renda extra para a sobrevivência da família, a permanência neste sistema de produção pode ser comprometida; nesse sentido, seria função das políticas públicas criar mecanismos de proteção e de incentivos especiais a tais produtores, uma vez que eles estão dispostos a produzir alimento mais saudável, a manter o equilíbrio ambiental, a gerar renda para a própria a família, mantendo seus integrantes no campo e gerando empregos; logo, prestam um serviço benéfico à sociedade com um todo, promovendo, enfim, o propagado desenvolvimento sustentável.

Fica claro que a produção orgânica e/ou agroecológica não é um nicho para todos, produzir desta forma é possível, contudo exige do produtor cuidados específicos, e maior dispêndio de atenção, tempo e mão-de-obra, e por que não dizer, depende quase que de uma vocação, pois as dificuldades encontradas no período de transição são inúmeras, o que leva muitos produtores a desistirem e voltarem ao método convencional.

A realidade que se encontrou nas visitas foi a de que os produtores comercializam seus produtos orgânicos com certificação agroecológica. A partir da revisão, debates e experiências visitadas, considera-se importante ressaltar que há diferenças entre a produção agroecológica e a orgânica. Enquanto a agroecológica é mais processual, articulando referências sociais, ambientais e econômicas, a orgânica refere-se especificamente a produtos livres de agrotóxicos e de outros componentes químicos de alta solubilidade.

Na prática, a Agroecologia se percebe como um conceito fechado, dependente do Estado, embora seja ligada ao mercado, ou seja, ela é contra o capitalismo (no conceito), mas depende dele (no mercado).

\section{Referências}

CAMPOS, F. R. Organização e estratégias de desenvolvimento e participação de mulheres e homens: estudo de caso Assentamento 8 de Junho - Laranjeiras do Sul/PR. Dissertação (Mestrado em Desenvolvimento Regional e Agronegócio) - Universidade Estadual do Oeste do Paraná, Toledo, 2011. 
CAPA. Centro de Apoio ao Pequeno Agricultor. Disponível em:

<http://www.capa.org.br/site/content/home/index.php>. Acesso em: 15 dez. 2013.

CAPORAL, Francisco Roberto. Agroecologia: uma nova ciência para apoiar a transição a agriculturas mais sustentáveis. Brasília: [s.n], 2009.

CAPORAL, Francisco R.; COSTABEBER, José A.; PAULUS, Gervásio. Agroecologia: matriz disciplinar ou novo paradigma para o desenvolvimento rural sustentável. Brasília, 2006.

CPRA. Centro Paranaense de Referência em Agroecologia. Disponível em: <http://www.cpra.pr.gov.br/modules/conteudo/conteudo.php?conteudo=7>. Acesso em: 29 nov. 2013.

CEZIMBRA, Elemar do N. Desenvolvimento socioambiental do assentamento Oito de junho. 2013. 113 p. Dissertação (Mestrado em Desenvolvimento Regional) - Universidade Tecnológica Federal do Paraná, Pato Branco, 2013.

DALGAARD Tommy; HUTCHINGS, Nicholas J.; PORTER, John R. Agroecology, scaling and interdisciplinarity. Agriculture, Ecosystems and Environment, n. 100, p. 39-51, 2003.

GLIESSMAN, Stephen. Agroecologia: processos ecológicos em agricultura sustentável. 2. ed. Porto Alegre. UFRGS. 2000.

GUHUR, Dominique M. P.; TONÁ, Nilciney. Agroecologia. In: CALDART, Roseli et al. (Orgs.) Dicionário da educação no campo. Rio de Janeiro: FIOCRUZ; São Paulo: Expressão Popular, 2012, p. 59-67.

IAPAR - Instituto Agronômico do Paraná. Relato do I Seminário de Agroecologia Brasil x França. Curitiba, 2013.

IPARDES. O mercado de orgânicos no Paraná: caracterização e tendências. Curitiba: IPARDES, 2007.

MARTIGNONI, Luciano. Lazer no assentamento rural Oito de junho: análise a partir da multifuncionalidade da agricultura. 2013. 131 p. Dissertação (Mestrado em Desenvolvimento Regional) - Universidade Tecnológica Federal do Paraná, Pato Branco, 2013.

MELÃO, Ivo B. Desenvolvimento rural sustentável a partir da Agroecologia e da agricultura orgânica: o caso do Paraná. Nota Técnica Ipardes, n. 8. Curitiba, 2010. Disponível em: <http://www.ipardes.gov.br/biblioteca/docs/NT_08_desenv_pdf>. Acesso em: 10 nov. 2013.

MIRANDA, Marcio; ZANDONÁ, João C.; COELHO, Solange M. da R. Construção da proposta de reestruturação para o "Centro Paranaense de Referência em Agroecologia". Resumos do VII Congresso Brasileiro de Agroecologia, Fortaleza, 12 a 16 de dezembro de 2011. Disponível em: <http://www.aba-Agroecologia.org.br/ojs2/ index.php/cad/article/view/11305/7845>. Acesso em: 10 nov. 2013. 
NAVARRO, Zander. Agroecologia: as coisas em seu lugar (A agronomia brasileira visita a terra dos duendes). Colóquio, Taquara, v. 10, n. 1, p. 11-45, 2013.

NORDER, L.A.C. Painel 1 - Agroecologia como campo científico: marco conceitual e ensino em Agroecologia. Londrina (Paraná), I Seminário de Agroecologia Brasil X França, 5 de dezembro (Centro de Difusão de Tecnologia de Londrina, I APAR - Instituto Agronômico do Paraná), 2013.

ROVER, Oscar José. Agroecologia, mercado e inovação social: o caso da Rede Ecovida de Agroecologia. Revista Ciências Sociais, Unisinos, São Leopoldo, v. 47, n. 1, p. 56-63, jan./abr. 2011. Disponível em: <http://revistas.unisinos.br/index.php/ciencias_sociais/ article/viewFile/1044/239>. Acesso em: 7 maio 2014.

SCHNEIDER, Sergio. Actividades rurales no agricolas y transformaciones de espacio rural: perspectivas recientes. Cuadernos de Desarrollo Rural, Bogotá, v. 1, n. 44, p. 11-40, 2000.

WEZEL, A. S. et al. Agroecology as a science, a movement and a practice. A review. In: Agronomy for Sustainable Development, Paris, n. 29, p. 503-515, 2009. 